\title{
Processing of Polypropylene-Organic Montmorillonite Nanocomposite by Equal Channel Multiangular Extrusion
}

\author{
V. A. Beloshenko, ${ }^{1}$ A. V. Voznyak, ${ }^{2}$ Yu. V. Voznyak, ${ }^{3}$ L. A. Novokshonova, \\ V. G. Grinyov, ${ }^{4}$ and V. G. Krasheninnikov ${ }^{4}$ \\ ${ }^{1}$ Donetsk Institute for Physics and Engineering Named after A. A. Galkin, National Academy of Sciences of Ukraine, \\ Pr. Nauki 46, Kiev 03028, Ukraine \\ ${ }^{2}$ Donetsk National University of Economics and Trade Named after M. Tugan-Baranovsky, Kurchatov Street, No. 13, \\ Krivoi Rog 50042, Ukraine \\ ${ }^{3}$ Centre of Molecular and Macromolecular Studies, Polish Academy of Sciences, Sienkiewicza Street, No. 112, 90363 Lodz, Poland \\ ${ }^{4}$ Semenov Institute of Chemical Physics, Russian Academy of Sciences, Kosygin Street, No. 4, Moscow 119991, Russia \\ Correspondence should be addressed to Yu. V. Voznyak; wozniak@cbmm.lodz.pl
}

Received 27 May 2016; Revised 29 August 2016; Accepted 25 September 2016

Academic Editor: Miriam Rafailovich

Copyright (C) 2016 V. A. Beloshenko et al. This is an open access article distributed under the Creative Commons Attribution License, which permits unrestricted use, distribution, and reproduction in any medium, provided the original work is properly cited.

By the example of polypropylene-organic montmorillonite composite (PP-OMMT), the abilities of the method of equal channel multiangular extrusion have been studied with respect to the modification of the structure and the properties of polymeric nanocomposites. With using X-ray structure analysis, TEM, DSC, and dilatometry, it has been demonstrated that this kind of processing provides an additional intercalation of the polymer into OMMT tactoids with the succeeding exfoliation and facilitates an increase in the aspect ratio, the degree of platelet orientation, the crystalline lamellar thickness, and a decrease in the dispersion of the crystallite thickness, as well as the formation of biaxial orientation of the OMMT and PP crystals. The observed structure rearrangements determine enhanced microhardness, ductility, and the heat distortion temperature of the PP-OMMT composite.

\section{Introduction}

Polymeric nanocomposites are of substantial scientific and practical interest due to possible formation of an enhanced level of physical and mechanical properties at extremely low content of a nanofiller [1]. The reason is creation of nanoscale structures where the filler particles are well stratified and dispersed within the polymer matrix. The efficiency of property enhancement is determined by the filler shape, strainstrength characteristics, the aspect ratio, volume fraction, and interfacial adhesion $[2,3]$. A special attention is attracted by layered nanofillers like montmorillonite, zirconium phosphate, and graphene that are composed of thin $(\sim 1 \mathrm{~nm})$ plate-like structures characterized by high surface area and aspect ratio. Being used as the second phase, they allow increase in the elasticity modulus and the yield strength, the heat distortion temperature, enhancement of gas barrier properties, flame retardancy, and UV resistance of polymeric composites [4].

Recent research efforts have focused on production of well-exfoliated nanocomposites with using various processing techniques, for example, in situ polymerization, emulsion polymerization, melt compounding, and sol-gel processing methods [5-16]. Unfortunately, no one provides control of the structural parameters of both the nanofiller (filler aspect ratio and orientation) and the polymeric matrix (crystalline lamellar thickness and lamellar orientation), to obtain additional facilities of the control of the morphology and the properties of polymer nanocomposites.

The studies [17-23] have shown that equal channel angular extrusion (ECAE) process permits alternation of the nanofiller aspect ratio and orientation, as well as the crystalline lamellar ones. In particular, it has been shown that, in semicrystalline polymer-based nanocomposites, the 
alignment of nanosized clay layers by ECAE has an effect on the nanoscopic orientation of crystalline lamellae, structural parameters of the nanoclay, and the polymer in nanocomposites. Some studies report that the ECAE can control the clay orientation in the composites, depending on the processing routes $[19,20,23]$. After processing the onepass ECAE, the nanoclays were shortened, well-aligned, and closely packed, and the crystalline lamellae were compressed and diagonally well oriented. The two-pass ECAE process with a $180^{\circ}$ rotation between the passes results in a random dispersion of the nanoclay particles and the recovery of the packed nanoclay interlayer spacing and the compressed lamellar long period. Creasy and Kang [18] found that ECAE can control the fiber orientation and the length of glass fiber/polyacetal composites, depending on the processing routes. $\mathrm{Li}$ et al. [22] also noticed that controlled nanoparticle orientation and effective exfoliation could be easily achieved through ECAE.

A promising variant of ECAE aimed at the structural modification of polymers and polymeric composites is equal channel multiple angular extrusion (ECMAE) that provides modification of the spatial orientation of the shear planes, the intensity, and the value of the accumulated strain per one pass [24]. By ECMAE, a unique set of the properties can be formed in semicrystalline polymers: high density and strain-stress characteristics combined with the minimum anisotropy [2527].

The present paper is aimed at the study of ECMAE abilities with respect to the modification of the structure and the properties of a polymeric nanocomposite, namely, polypropylene-organic montmorillonite (PP-OMMT).

\section{Experiment}

2.1. Materials. Isotactic PP (Moscow Naphta Processing Plant, Russia) with a melt flow index of $0.6 \mathrm{~g} / 10 \mathrm{~min}(2.16 \mathrm{~kg}$, $230^{\circ} \mathrm{C}$, ASTM D1238), $\mathrm{Mw}=6.3 \times 105 \mathrm{~g} / \mathrm{mol}$, and $\mathrm{Mw} / \mathrm{Mn}=$ 3.5 was used as the polymers matrix. The modified montmorillonite (Cloisite 20A) produced by Southern Clay Products, with the particle size within the range of $6-8 \mu \mathrm{m}$, was used as the filler.

\subsection{Sample Preparation}

Preparation of the Nanocomposites. The composites were prepared by the melt mixing in a two-roller mixing chamber (Institute of Chemical Physics, Moscow, Russia) at $453 \mathrm{~K}$ and with a rotor rotation speed of $90 \mathrm{rpm}$. First, PP was meltblended with stabilizers of the thermooxidative degradation (0.3 wt.\% of topanol and $0.5 \mathrm{wt} . \%$ of dilauriltiodipropionate) for $3 \mathrm{~min}$. Then the OMMT was added slowly over $3 \mathrm{~min}$, and the mixture was compounded for $10 \mathrm{~min}$. The filler concentration was $5 \mathrm{vol} . \%$, permitting obtaining the original composites characterized by the dispersion of the OMMT particles within the polymeric matrix and the optimum combination of stress-strain characteristics.

Procedure of Pressing of the ECMAE Billets. The composites were heated up to $433 \mathrm{~K}$ in a closed mould of $15 \mathrm{~mm}$ in

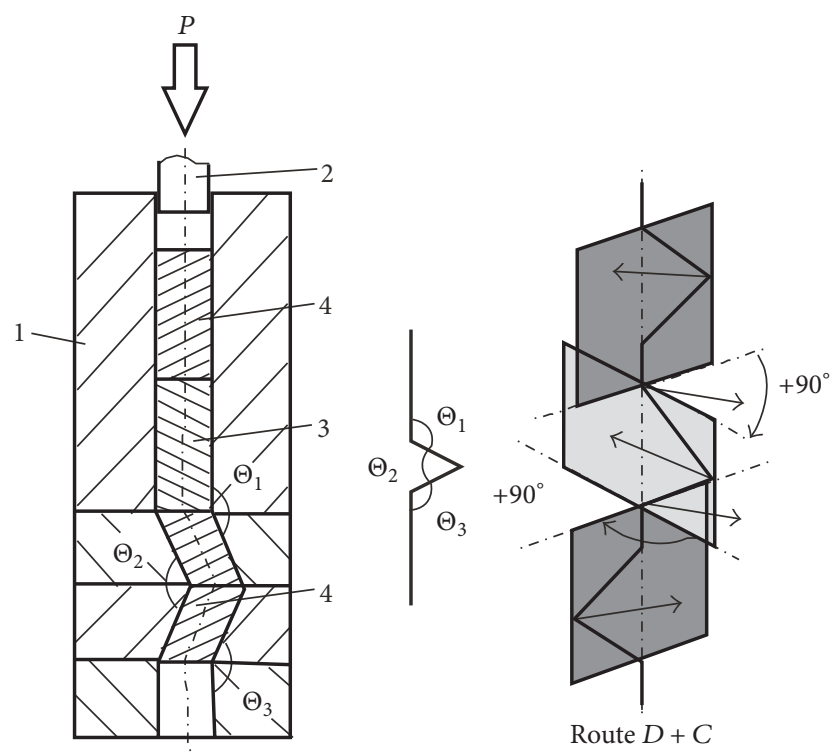

FIGURE 1: Scheme of ECMAE process: 1: die; 2: punch; 3: polymeric billet; 4: sacrified billets.

diameter. The composites were heated in the closed mould up to $433 \mathrm{~K}$, thermostated at $463 \pm 2 \mathrm{~K}$ for $10 \mathrm{~min}$, and air-cooled down to $323 \mathrm{~K}$ under the pressure of $10 \mathrm{MPa}$. The cooling rate was $\sim 1.2-1.4 \mathrm{deg}$./min.

Equal Channel Angular Extrusion. Equal channel multiple angular extrusion was performed to alter the aspect ratio and orientation of the polymer matrix and clay nanoparticles. In Figure 1, the scheme of ECMAE is presented. A polymeric billet is extruded through the device composed of a few pairs of the channels of the same diameter that intersect at the set angles $\Theta_{i}$. To fix the direction of the billet motion, the inlet and outlet channels are vertically coaxial. The oblique channels are pairwise located in the planes that can be rotated through the vertical axis to realize different routes of deformation (the variants of spatial evolution). ECMAE was carried out at deformation intensity $\Delta \Gamma=0.83$, the accumulated strain $\varepsilon=4.4$, the extrusion temperature of $413 \mathrm{~K}$, and the extrusion rate of $0.6 \mathrm{~mm} / \mathrm{s}$. As a deformation route, route $D+C$ was selected, where the pairwise connected oblique deforming channels were in perpendicular planes rotated through the vertical axis in increments of $90^{\circ}$, being separated by the vertical channels (Figure 1); the detailed description was reported in [27]. The above processing condition allowed for the generation of maximal physical and mechanical properties of the PP matrix. Both the extrudates and the original billets were of the cylinder shape of $15 \mathrm{~mm}$ in diameter and $50 \mathrm{~mm}$ in length.

\subsection{Characterization}

2.3.1. Microhardness Test. Microhardness $H$ was determined using a microhardness tester of the PMT-3 type. For $H$, the relative error was not higher than 5\%. The uniformity of $H$ distribution over the sections of extrudates was estimated by the value of dispersion $D_{H}$ calculated as 
$D_{H}=\sqrt{(1 / n(n-1)) \sum_{i=1}^{n}\left(\bar{H}-H_{i}\right)^{2}}$, where $n$ was the number of measurements, $H_{i}$ was the result of an individual measurement of the microhardness value, and $\bar{H}$ was the average microhardness value. The anisotropy of microhardness $\Delta H$ was found as $\Delta H=1-H^{\perp} / H^{\|}$, where $\bar{H}^{\perp}$ and $\bar{H}^{\|}$were the average values of microhardness in the transverse and longitudinal sections, respectively [28].

2.3.2. Tensile Testing. The characteristics of the mechanical properties of the materials before and after ECMAE (modulus of elasticity $E$, yield strength $\sigma_{y}$, tensile strength $\sigma_{T}$, and strain at break $\varepsilon_{b}$ ) were measured by the universal test installation by "JJ Instruments T5K" at the room temperature (294 K) in the uniaxial tension mode. The deformation rate was $1 \mathrm{~min}^{-1}$.

2.3.3. Differential Scanning Calorimetry (DSC). The thermal characteristics were probed with DSC DSC-204 F1 differential scanning calorimeter ("Netzsch", Germany) during heating from $293 \mathrm{~K}$ to $453 \mathrm{~K}$ at the rate of $5 \mathrm{deg}$./ $\mathrm{min}$ in argon flux. The specific heat flow from the melting peak $(\mathrm{W} / \mathrm{g})$ was corrected for the mass of PP in the nanocomposite. The PP matrix crystallinity $\chi_{c}^{\mathrm{DSC}}$ in the nanocomposites was calculated with the value of melting enthalpy; for $100 \%$ crystalline, PP was $209 \mathrm{~J} / \mathrm{g}$.

2.3.4. Dilatometry. The changes in linear dimensions of specimens cut in longitudinal and transverse directions with respect to extrudate's axis were determined by a dilatometer DIL $402 \mathrm{PC} / 4$, Netzsch, the heating rate was equal to $1 \mathrm{deg} . / \mathrm{min}$.

2.3.5. Transmission Electron Microscopy (TEM). TEM was performed with using JEM-200A by "JEOL" under the accelerating voltage of $200 \mathrm{kV}$. The replica of the fracture surface was obtained as follows. The roentgen film (the matrix) was wetted by acetone and sticked on the fracture surface. After the drying, the film was separated and a thin carbon layer was applied on the obtained pattern. The test of the carbon replica was made after the separation from the matrix.

A semiautomated image analysis scheme was carried out to quantify the morphological variations in the nanofiller structures. Three different TEM images from three different regions of a sample were used to ensure the statistical significance of the image analysis scheme. The aspect ratios $(\alpha)$ of dispersed platelets were determined by

$$
\alpha=\frac{\bar{l}}{\bar{h}}
$$

where $\bar{l}$ was the mean platelet length and $\bar{h}$ was the mean platelet thickness.

The degree of platelet orientation $(S)$ was defined as

$$
S=\sqrt{\frac{\sum_{i=1}^{N}\left(\Phi_{i}-\bar{\Phi}\right)^{2}}{N}},
$$

where $\Phi_{i}$ was the actual platelet orientation $\left(0^{\circ} \leq \bar{\Phi} \leq 90^{\circ}\right)$ and $\bar{\Phi}$ was the mean platelet orientation.

2.3.6. Wide-Angle X-Ray Scattering. The X-ray diffraction (XRD) studies were done by the method of wide-angle $\mathrm{X}$ ray scattering with using a X-ray diffractometer. Mn-filtrated $\mathrm{FeK}_{\alpha}$-radiation was used in this case. The patterns were taken in the diffraction mode (the Bragg-Brentano focusing). To evaluate the degree of crystallinity correctly, the method of artificial randomization was applied. The method implied cutting of the tested material by a sharp blade into the pieces of $0.5 \times 0.5 \times 0.5 \mathrm{~mm}$ in size that were placed into a cavity, $4.0 \mathrm{~mm}$ thick. As compared with other methods of reduction, the selected randomization minimized the impact of shear stresses and the local heating on the structure of the material.

Using Matthews method, we evaluated the relative crystallization degree $\chi_{c}^{\text {WAXS }}$ by the following formula:

$$
\chi_{c}^{\mathrm{WAXs}}=\frac{\vartheta_{c}}{\vartheta_{c}+\vartheta_{a}},
$$

where $\vartheta_{c}$ was the area below the crystal reflexes and $\left(\vartheta_{c}+\vartheta_{a}\right)$ was the total area below the coherent scattering curve.

To estimate the function of space orientation of crystallites, the scanning was accomplished in increments of $5^{\circ}$ by sample rotation in the azimuthal direction from the angle corresponding to the direction normal to the extrudate axis (these are angles of $90^{\circ}$ and $270^{\circ}$ ). The detector was fixed at the scattering angle corresponding to the top of a diffraction maximum with an index of 110 with the top at $14.14^{\circ}$. As a measure of the total share of oriented material, the ratio of integral intensities of azimuthal scanning, $I_{\max }$, within the angle range from $0^{\circ}$ to $180^{\circ}$ was used, being separated from isotropic scattering to the total integral intensity.

\section{Results and Discussion}

In Figure 2, wide-angle diffraction patterns of the original OMMT, PP-OMMT composite before and after ECMAE are presented. The main specific feature of the curve of OMMT wide-angle scattering is the existence of an intensive maximum with the peak at the scattering angle of 3.2 degrees that corresponds to the periodicity of $2.76 \mathrm{~nm}$. Besides the crystal maximums typical of PP, the PP-OMMT composite produced by melt mixing is characterized by a substantial low-angle diffusion component in the angular range from the minimal registered angle to approximately 7 degrees and the diffraction maximum of OMMT at 2.3 degrees associated with the periodicity of $3.84 \mathrm{~nm}$. The presence of the above component is not characteristic of the neat PP, being related to the presence of nanodispersed material of the filler. In the case of ECMAE, a substantial (two- or threefold) reduction of the integral intensity of the low-angle contribution of the nanofiller and the vanishing diffraction maximum of OMMT are registered that can be the results of the succeeding increase in the interlayer periodicity of OMMT and the shift of the maximum to the low-angle region out of the reach of the used diffractometer, respectively. The observed changes in the form of the wide-angle diffraction patterns 
TABLE 1: Structural, physical, and mechanical characteristics of the PP-OMMT nanocomposite.

\begin{tabular}{|c|c|c|c|c|c|c|c|c|c|c|c|c|}
\hline Treatment & $\alpha$ & $S$, deg. & $D_{H}$ & $\Delta H$ & $\bar{H}^{\perp}$ & $\sigma_{T}$ & $\begin{array}{l}E_{c} / E_{m} \\
E_{c}^{e} / E_{c}\end{array}$ & $\varepsilon_{b}, \%$ & $\chi_{c}^{\text {WAXS }}$ & $\chi_{c}^{\mathrm{DSC}}$ & $T_{\text {onset }}$ & $T_{\max }$ \\
\hline Melt mixing & 90 & 36 & 2.17 & 0.07 & $65 \pm 2.6$ & $12.4 \pm 3.7$ & 1.30 & $3 \pm 1$ & 0.48 & 0.42 & 397 & 439 \\
\hline ECMAE & 150 & 51 & 0.53 & 0.03 & $90 \pm 3.0$ & $16.8 \pm 3.8$ & 0.92 & $7 \pm 1$ & 0.52 & 0.42 & 418 & 442 \\
\hline
\end{tabular}

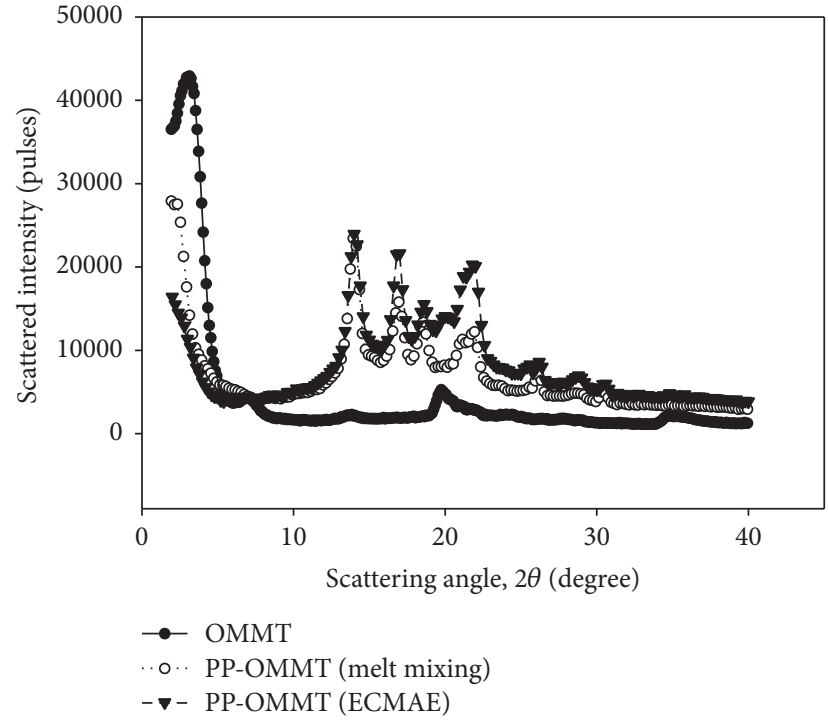

FIGURE 2: XRD patterns of OMMT and PP-OMMT composites.

of the tested materials are evidences of the fact that the melt mixing determines the intercalation of the fragments of polymer molecules to the interlayer space of OMMT, and the succeeding ECMAE results in the further increase in the degree of intercalation and facilitates the effective exfoliation of the tactoids of the nanofiller. The last statement is confirmed by the results of TEM studies.

TEM images indicating the nanoclay structures of the initial and ECMAE-processed nanocomposites demonstrate that, in the original PP-OMMT composite, the thickness of the layer of the filler particles is about 60-90 nm (Figure 3(a)). ECMAE processing results in the reduction of the thickness down to $15-30 \mathrm{~nm}$ (Figure 3(b)).

Morphological alterations of the nanoclays (the aspect ratio $\alpha$ and the degree of platelet orientation $S$ ) with respect to the ECMAE passes were observed (Table 1). After the ECMAE process, an increase in the nanoclay aspect ratio as well as in the degree of platelet orientation was registered.

According to the filler-based micromechanical concepts $[29,30]$, an increase in the aspect ratio $\alpha$ and a reduction of the orientation $S$ of the nanoclays should be accompanied by an increase in the modulus of elasticity and the tensile strength of the composites. At the same time, the determining factor of the above characteristics is the aspect ratio. Table 1 demonstrates the results of the measurements of the microhardness and the mechanical tensile tests. It is seen that the microhardness and the tensile strength of the composites are increased after the ECMAE processing and the elasticity modulus is slightly reduced. An increase in the tensile strength correlates to the aspect ratio enhanced in the course of ECMAE processing due to the reduced thickness of the layer of the particles with the particle length conserved. A decrease in the modulus of elasticity can be related to both increased degree of platelet orientation and weakened "reinforcing effect" of nanoparticles. The last fact is confirmed by the character of the change of the ratio of the elasticity moduli of the original PP $\left(E_{m}\right)$ and PP-OMMT composite before and after ECMAE, $E_{c}$, and $E_{c}^{e}$, respectively (Table 1). It is seen that the relative modulus of elasticity $E_{c} / E_{m}>1$; at the same time $E_{c}^{e} / E_{c}<1$. Furthermore, from Table 1 it is evident that ECMAE also decreases the value of microhardness dispersion $D_{H}$ over the cross section of the extrudate compared with the initial composite, due to the more uniform distribution of nanofiller in the polymer matrix.

Enhancement of the ductility (strain at break) of the PP-OMMT composites after ECMAE (Table 1) is probably determined by an increase in the degree of platelet orientation and the formation of a biaxially oriented structure providing conserved plasticity of the polymeric matrix after ECMAE processing $[26,27]$. As shown in $[27,31]$, the reason is that a net of interwoven fibrils is formed in the extrudates of semicrystalline polymers with the biaxially oriented structure. The net suppresses the evolution of the main crack and provides successive involvement of two groups of the oriented macromolecules into the process of plastic flow in the course of tension. In the case of PP-OMMT composites, an assumption about the biaxial orientation of the fibrils is confirmed by low anisotropy of microhardness (Table 1), the data of X-ray structure analysis, and the results of dilatometry.

In Figure 4, the functions of spatial orientation of OMMT and PP crystals in composites produced by melt mixing and ECMAE are presented. It is seen that, in the case of melt mixing of composites, a uniform distribution of the orientation directions of PP crystals takes place, being accompanied by an insignificant preferred orientation of OMMT crystals over the composite volume. In ECMAEprocessed composites, formation of well-defined directions of the preferred orientations of the PP and OMMT crystals is observed. An evidence is the emergence of the related peaks at the azimuthal intensity profiles. The position and the height of the peaks determine the corresponding directions of preferential orientation and the part of the oriented crystals. It is seen that the OMMT crystals are mostly aligned with the longitudinal axis of the extrudate and normal to it. At the same time, the PP crystals deviate at an angle of $30^{\circ}$ from the orientation of the OMMT crystals. The total angle between two preferential orientations of both OMMT and PP crystals is about $90^{\circ}$, that is, an evidence of formation of biaxial character of orientation. It should be also noted that, at the 


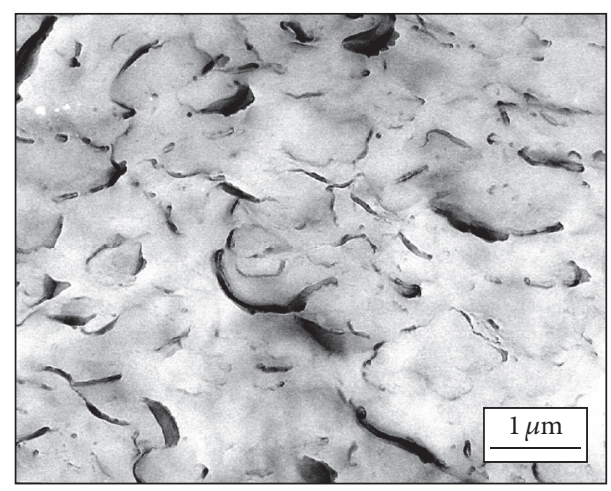

(a)

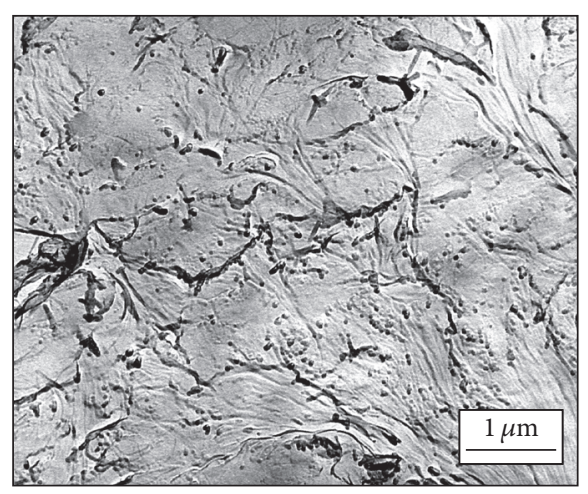

(b)

FIGURE 3: TEM micrographs of the structure of PP-OMMT: (a) the initial one; (b) after ECMAE.

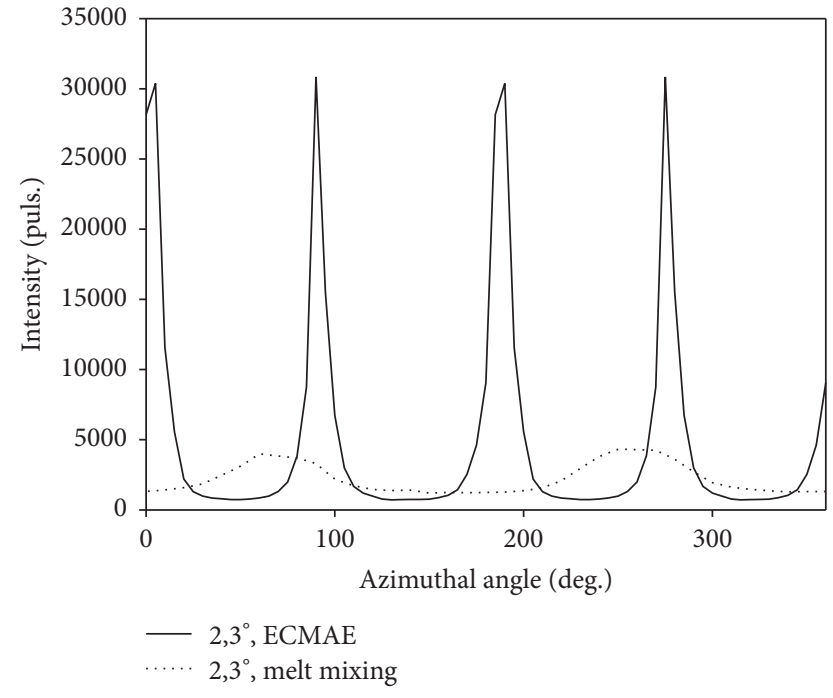

(a)

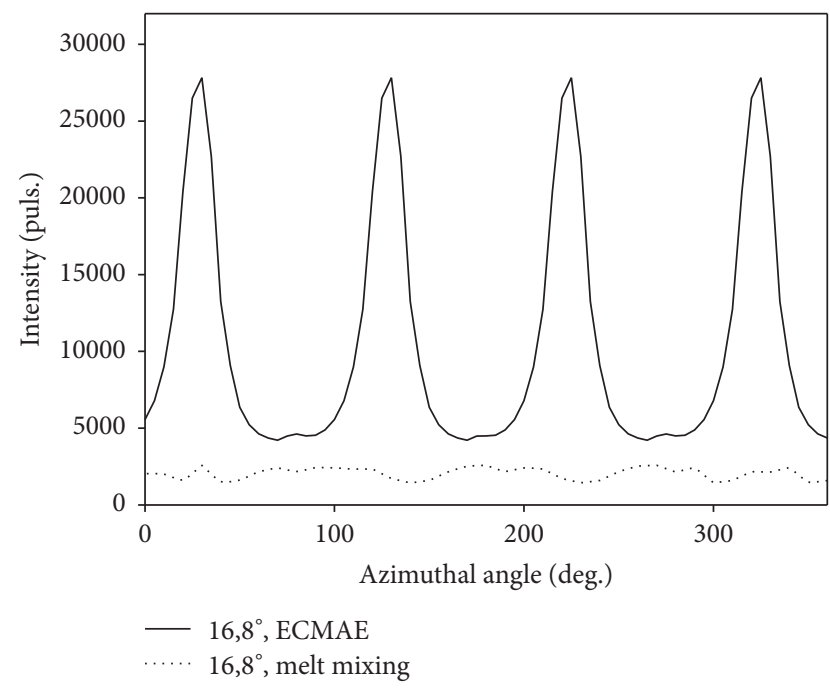

(b)

FIGURE 4: The results of azimuthal scanning of the detector located at fixed scattering angles.

same time, a uniform distribution along the related directions of the preferred orientation is registered, being confirmed by the same intensity of the peaks.

In Figure 5, temperature dependencies of the relative elongation $\left(\Delta l / l_{0}(T)\right.$ where $l_{0}$ is the initial length of the specimen, $l$ is the current length of the specimen during heating, and $T$ is the temperature) of the PP-OMMT samples cut in the longitudinal and transverse direction with respect to the extrudate axis are presented. Contrary to the behavior of $\Delta l / l_{0}(T)$ of the original sample (the length increases due to the thermal expansion when the temperature grows), the samples cut of the composite subjected to ECMAE are characterized by the reduced $\Delta l / l_{0}$ within the whole tested temperature range. At the same time, $\Delta l / l_{0}(T)$ of the samples cut in the longitudinal and transverse direction with respect to the extrudate axis almost coincide.

According to [27], the reason can be the formation of a net of elongated polymeric chains within extrudates. The chains are distributed evenly in two perpendicular directions, being of a comparable degree of molecular orientation. It should be noted that, in the case of the composite exposed to ECMAE, an increase (from $374 \mathrm{~K}$ to $383 \mathrm{~K}$ ) in the upper limit of the temperature range, where $\Delta l / l_{0}$ is constant, is observed, that is, the heat distortion temperature growths, as compared to the original composite.

Formation of orientation order in a polymeric matrix is also responsible for an increase in the microhardness and the tensile strength. However different changes on the relative modulus of elasticity of composites before and after ECMAE (Table 1) are the evidences of the fact that orientation of the transition layers results in their partial softening and/or mechanical destruction.

Reference [32] considers three main types of dependencies of $E$ on the volume filling degree $\varphi$ : the perfect bond between the matrix and the filler (case I), an absence of adhesion and the presence of the friction force between the matrix and filler particles (II), and an absence of adhesion and friction force (III). These dependencies are given in the form of the ratio of the composite modulus $E_{c}$ and the polymer matrix $E_{m}$ as a function of $\varphi$. In the first case, one observes 


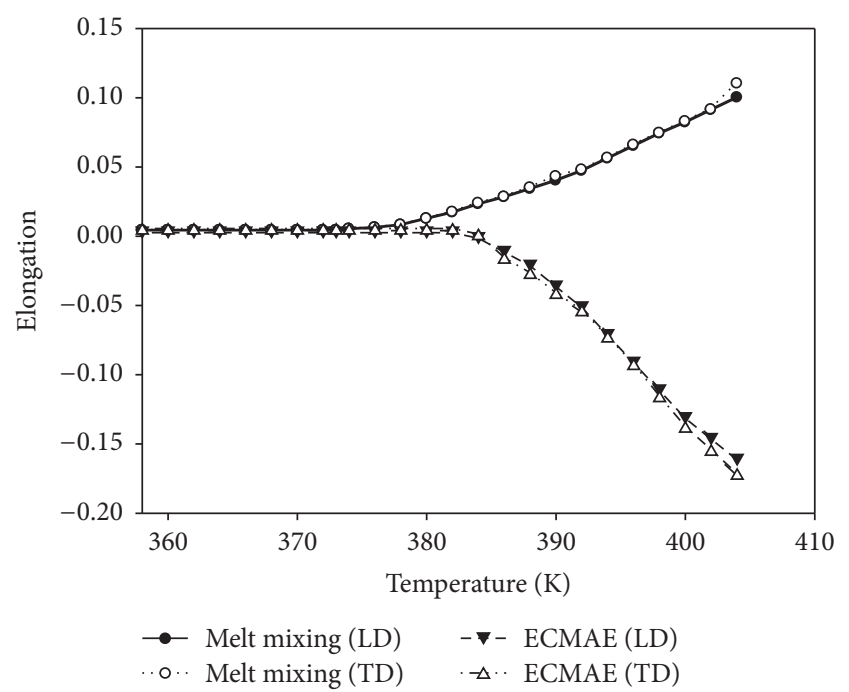

FIgURE 5: Temperature dependencies of the elongation of the PPOMMT. LD is the longitudinal direction; TD is the transversal one.

a considerable increase of $E_{c} / E_{m}$ with the growth of $\varphi$. In the second case, there is a small increase, and a decrease in $E_{c} / E_{m}$ is found in the third case. The decrease in $E$ caused by the above facts prevails over the increase in $E$ achieved by the orientation of the polymer matrix macromolecules. This assumption is confirmed by the decrease in $E$ after ECMAE due to reduction of the adhesion strength in the polymerfiller, as mentioned above.

It is known that the lamellae orientation in the dispersed platelets may also affect the polymer matrix morphological features, such as crystalline lamellar thickness and crystallinity. The performed WAXS and DSC tests (Figure 6) have shown that the degree of crystallinity and the melting peak temperature $T_{\max }$ are weakly changed in composites after ECMAE, but the onset temperature $T_{\text {onset }}$ is substantially increased and the width of the melting peak is reduced (Table 1). It can be supposed that higher values of $T_{\text {onset }}$ are related to the enhanced part of larger crystallites and/or the degree of their perfection in extrudates as compared to the original composites because of destruction of the thinnest crystallites and/or strain-induced crystallization [33-35]. Reduced peak width is an evidence of lower dispersion of the crystallite thickness.

The schemes of the main structural features responsible for the formed set of physical and mechanical characteristics in the case of composites produced by melt mixing and melt mixing completed with ECMAE are presented in Figure 7. According to the model suggested by $\mathrm{Ma}$ et al. [21], the clay platelets with their planes are oriented along either the shear direction or the major strain axis. The orientation of the clay layers induces the orientation of molecular chains and crystal lamellae. Besides, the orientation of crystal lamellae lags behind that of the macromolecular chains, which is almost oriented along the direction of clay layers. On this basis, it can be supposed that, in the first case, the structure of the composite is composed of a disoriented polymeric matrix and almost randomly oriented particles of OMMT

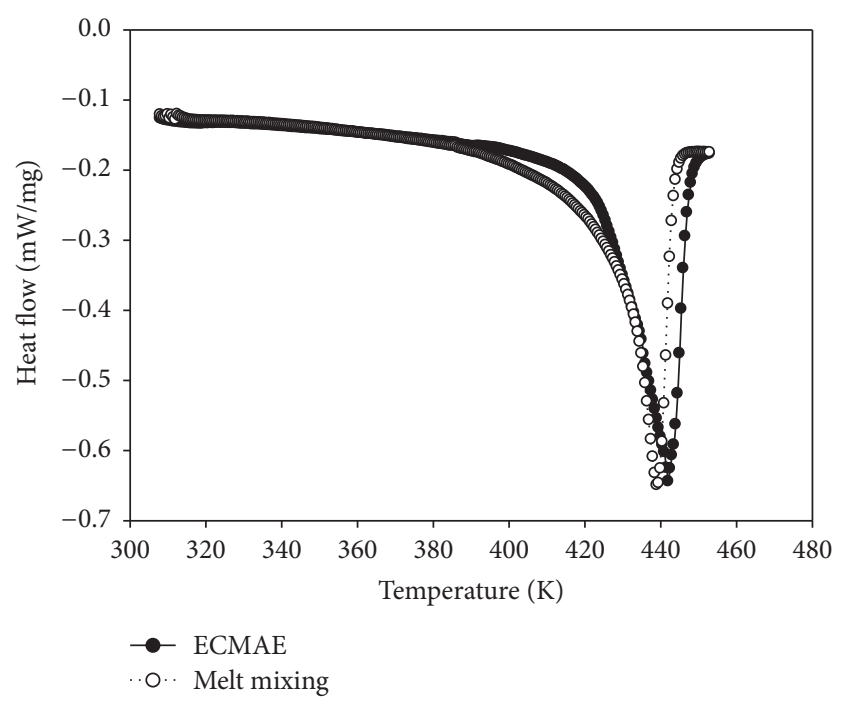

FIGURE 6: DSC traces for specimens of PP-OMMT.

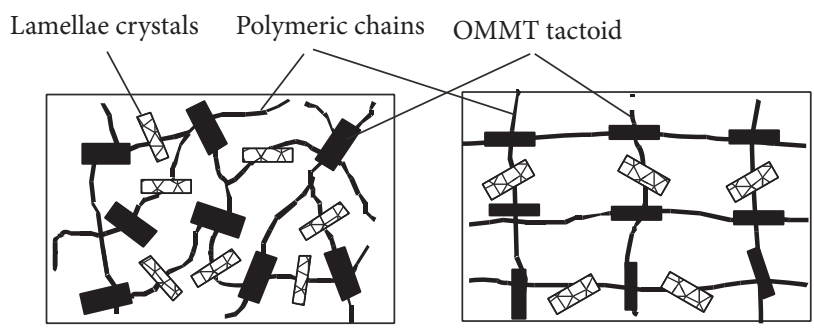

(a)

(b)

FIGURE 7: Schematic structures of the PP-OMMT composites after melt mixing (a) and ECMAE (b).

(Figure 7(a)). In the second case, biaxial orientation of elongated polymeric chains is found, being combined with orthogonal character of the distribution of exfoliated particles of the filler that are characterized by a higher aspect ratio (Figure 7(b)). This type of the structure determines enhanced values of microhardness and the heat distortion temperature of composites. Besides, an enhanced impact strength is expected to be provided [36].

\section{Conclusion}

ECMAE is an effective process aimed at the alternation of the nanofiller aspect ratio and the degree of platelet orientation, as well as the matrix morphological features, such as lamellar orientation, crystalline lamellar thickness, and the degree of perfection. It is shown that the processing of the PP-OMMT composite results in the increased aspect ratio and the degree of platelet orientation, as compared to the melt mixing. The exfoliation of the filler particles as well as the formation of the orientation order in the polymeric matrix, increment of the part of larger crystallites, and lower dispersion of the crystallite thickness is provided. As a result, an increase in microhardness is achieved, combined with more homogeneous distribution over the cross section of the sample, higher 
strain-strength characteristics of the composites, and the heat distortion temperature.

\section{Competing Interests}

The authors declare that they have no competing interests.

\section{Acknowledgments}

The authors express their gratitude to V. A. Glasunova for assistance in TEM investigations.

\section{References}

[1] K. Ja. Yaraman and S. Kumar, "Polypropylene layered silicate nanocomposites," in Polymer Nanocomposites, Y.-W. Mai and Z.-Z. Yu, Eds., pp. 130-151, Woodhead Publishing, Cambridge, Mass, USA, 2006.

[2] G. M. Kim, D. H. Lee, B. Hoffmann, J. Kressler, and G. Stöppelmann, "Influence of nanofillers on the deformation process in layered silicate/polyamide-12 nanocomposites," Polymer, vol. 42, no. 3, pp. 1095-1100, 2001.

[3] L. Zhang, Y. Wang, Y. Sui, and D. Yu, "Morphology and mechanical properties of clay/styrene-butadiene rubber nanocomposites," Journal of Applied Polymer Science, vol. 78, no. 11, pp. 1873$1878,2000$.

[4] A. Usuki, Y. Kojima, and M. Kawaski, "Synthesis and characterization of a nylon 6-clay hybrid," Polymer Preprints, vol. 28, p. 447, 1987.

[5] S. I. Marras, A. Tsimpliaraki, I. Zuburtikudis, and C. Panayiotou, "Morphological, thermal, and mechanical characteristics of polymer/layered silicate nanocomposites: the role of filler modification level," Polymer Engineering and Science, vol. 49, no. 6, pp. 1206-1217, 2009.

[6] M. Ataeefard and S. Moradian, "Polypropylene/organoclay nanocomposites: effects of clay content on properties," PolymerPlastics Technology and Engineering, vol. 50, no. 7, pp. 732-739, 2011.

[7] K. S. Santos, S. A. Liberman, M. A. S. Oviedo, and R. S. Mauler, "Polyolefin-based Nanocomposite: the effect of organoclay modifier," Journal of Polymer Science, Part B: Polymer Physics, vol. 46, no. 23, pp. 2519-2531, 2008.

[8] H. Krump, A. S. Luyt, and I. Hudec, "Effect of different modified clays on the thermal and physical properties of polypropylenemontmorillonite nanocomposites," Materials Letters, vol. 60, no. 23, pp. 2877-2880, 2006.

[9] Y. Dong and D. Bhattacharyya, "Investigation on the competing effects of clay dispersion and matrix plasticisation for polypropylene/clay nanocomposites. Part I: morphology and mechanical properties," Journal of Materials Science, vol. 47, no. 8, pp. 3900-3912, 2012.

[10] Y. Al Herz, C. M. R. Madhuranthakam, A. Elkamel, and V. Mittal, "Optimal mechanical and gas permeation properties of polypropylene-organically modified montmorillonite (PPOMMT) nanocomposites," Journal of Polymer Engineering, vol. 34, no. 6, pp. 501-509, 2014.

[11] V. Mittal, "Mechanical and gas permeation properties of compatibilized polypropylene-layered silicate nanocomposites," Journal of Applied Polymer Science, vol. 107, no. 2, pp. 13501361, 2008.
[12] S. S. Ray and M. Okamoto, "Polymer/layered silicate nanocomposites: a review from preparation to processing," Progress in Polymer Science, vol. 28, no. 11, pp. 1539-1641, 2003.

[13] N. Ristolainen, U. Vainio, S. Paavola, M. Torkkeli, R. Serimaa, and J. Seppälä, "Polypropylene/organoclay nanocomposites compatibilized with hydroxyl-functional polypropylenes," Journal of Polymer Science, Part B: Polymer Physics, vol. 43, no. 14, pp. 1892-1903, 2005.

[14] K. S. Santos, S. A. Liberman, M. A. S. Oviedo, and R. S. Mauler, "Polyolefin-based nanocomposite: the effect of organoclay modifier," Journal of Polymer Science, Part B: Polymer Physics, vol. 46, no. 23, pp. 2519-2531, 2008.

[15] M. W. Spencer, D. L. Hunter, B. W. Knesek, and D. R. Paul, "Morphology and properties of polypropylene nanocomposites based on a silanized organoclay," Polymer, vol. 52, no. 23, pp. 5369-5377, 2011.

[16] E. V. Kuvardina, L. A. Novokshonova, S. M. Lomakin, S. A. Timan, and I. A. Tchmutin, "Effect of the graphite nanoplatelet size on the mechanical, thermal, and electrical properties of polypropylene/exfoliated graphite nanocomposites," Journal of Applied Polymer Science, vol. 128, no. 3, pp. 1417-1424, 2013.

[17] T. S. Creasy and Y. S. Kang, "Fiber orientation during equal channel angular extrusion of short fiber reinforced thermoplastics," Journal of Thermoplastic Composite Materials, vol. 17, no. 3, pp. 205-227, 2004.

[18] T. S. Creasy and Y. S. Kang, "Fibre fracture during equal-channel angular extrusion of short fibre-reinforced thermoplastics," Journal of Materials Processing Technology, vol. 160, no. 1, pp. 90-98, 2005.

[19] J.-I. Weon and H.-J. Sue, "Effects of clay orientation and aspect ratio on mechanical behavior of nylon-6 nanocomposite," Polymer, vol. 46, no. 17, pp. 6325-6334, 2005.

[20] J.-I. Weon, Z.-Y. Xia, and H.-J. Sue, "Morphological characterization of nylon-6 nanocomposite following a large-scale simple shear process," Journal of Polymer Science, Part B: Polymer Physics, vol. 43, no. 24, pp. 3555-3566, 2005.

[21] J. Ma, G. P. Simon, and G. H. Edward, "The effect of shear deformation on nylon- 6 and two types of nylon-6/clay nanocomposite," Macromolecules, vol. 41, no. 2, pp. 409-420, 2008.

[22] H. Li, X. Huang, C. Huang, and Y. Zhao, "An investigation about solid equal channel angular extrusion on polypropylene/organic montmorillonite composite," Journal of Applied Polymer Science, vol. 123, no. 4, pp. 2222-2227, 2012.

[23] Y. R. Seo and J.-I. Weon, "Manipulation of nanofiller and polymer structures by using equal channel angular extrusion," Journal of the Korean Physical Society, vol. 63, no. 1, pp. 114-119, 2013.

[24] V. A. Beloshenko, V. N. Varyukhin, A. V. Voznyak, and Y. Voznyak, "Equal-channel multiangular extrusion of semicrystalline polymers," Polymer Engineering and Science, vol. 50, no. 5, pp. 1000-1006, 2010.

[25] V. A. Beloshenko, V. N. Varyukhin, A. V. Voznyak, and Yu. V. Voznyak, "Polyoxymethylene orientation by equal-channel multiple angular extrusion," Journal of Applied Polymer Science, vol. 126, no. 3, pp. 837-844, 2012.

[26] V. A. Beloshenko, A. V. Voznyak, Y. V. Voznyak, and G. V. Dudarenko, "Equal-channel multiple angular extrusion of polyethylene," Journal of Applied Polymer Science, vol. 127, no. 2, pp. 1377-1386, 2013.

[27] V. A. Beloshenko, A. V. Voznyak, and Y. V. Voznyak, "Control of the mechanical and thermal properties of semicrystalline 
polymers via a new processing route of the equal channel multiple angular extrusion," Polymer Engineering and Science, vol. 54, no. 3, pp. 531-539, 2014.

[28] A. Flores, F. Ania, and F. J. Baltá-Calleja, "From the glassy state to ordered polymer structures: a microhardness study," Polymer, vol. 50, no. 3, pp. 729-746, 2009.

[29] N. Sheng, M. C. Boyce, D. M. Parks, G. C. Rutledge, J. I. Abes, and R. E. Cohen, "Modeling properties of nylon 6/clay nanocomposites using composite theories," Polymer, vol. 44, no. 17, pp. 4993-5013, 2003.

[30] T. D. Fornes and D. R. Paul, "Modeling properties of nylon 6/clay nanocomposites using composite theories," Polymer, vol. 44, no. 17, pp. 4993-5013, 2003.

[31] V. A. Beloshenko, A. V. Voznyak, and Y. V. Voznyak, "Specific features of plastic flow of biaxially oriented flexible-chain semicrystalline polymers," Doklady Physical Chemistry, vol. 457, no. 2, pp. 117-119, 2014.

[32] R. Hill, "Elastic properties of reinforced solids: some theoretical principles," Journal of the Mechanics and Physics of Solids, vol. 11, no. 5, pp. 357-372, 1963.

[33] Z. Bartczak and E. Lezak, "Evolution of lamellar orientation and crystalline texture of various polyethylenes and ethylene-based copolymers in plane-strain compression," Polymer, vol. 46, no. 16, pp. 6050-6063, 2005.

[34] Z. Bartczak and M. Kozanecki, "Influence of molecular parameters on high-strain deformation of polyethylene in the planestrain compression. Part I. Stress-strain behavior," Polymer, vol. 46, no. 19, pp. 8210-8221, 2005.

[35] T. Kazmierczak, A. Galeski, and A. S. Argon, "Plastic deformation of polyethylene crystals as a function of crystal thickness and compression rate," Polymer, vol. 46, no. 21, pp. 8926-8936, 2005.

[36] V. A. Beloshenko, A. V. Voznyak, and Y. V. Voznyak, "Effects of equal-channel, multiple-angular extrusion on the physical and mechanical properties of glassy polymers," Journal of Applied Polymer Science, vol. 132, no. 27, Article ID 42180, 2015. 

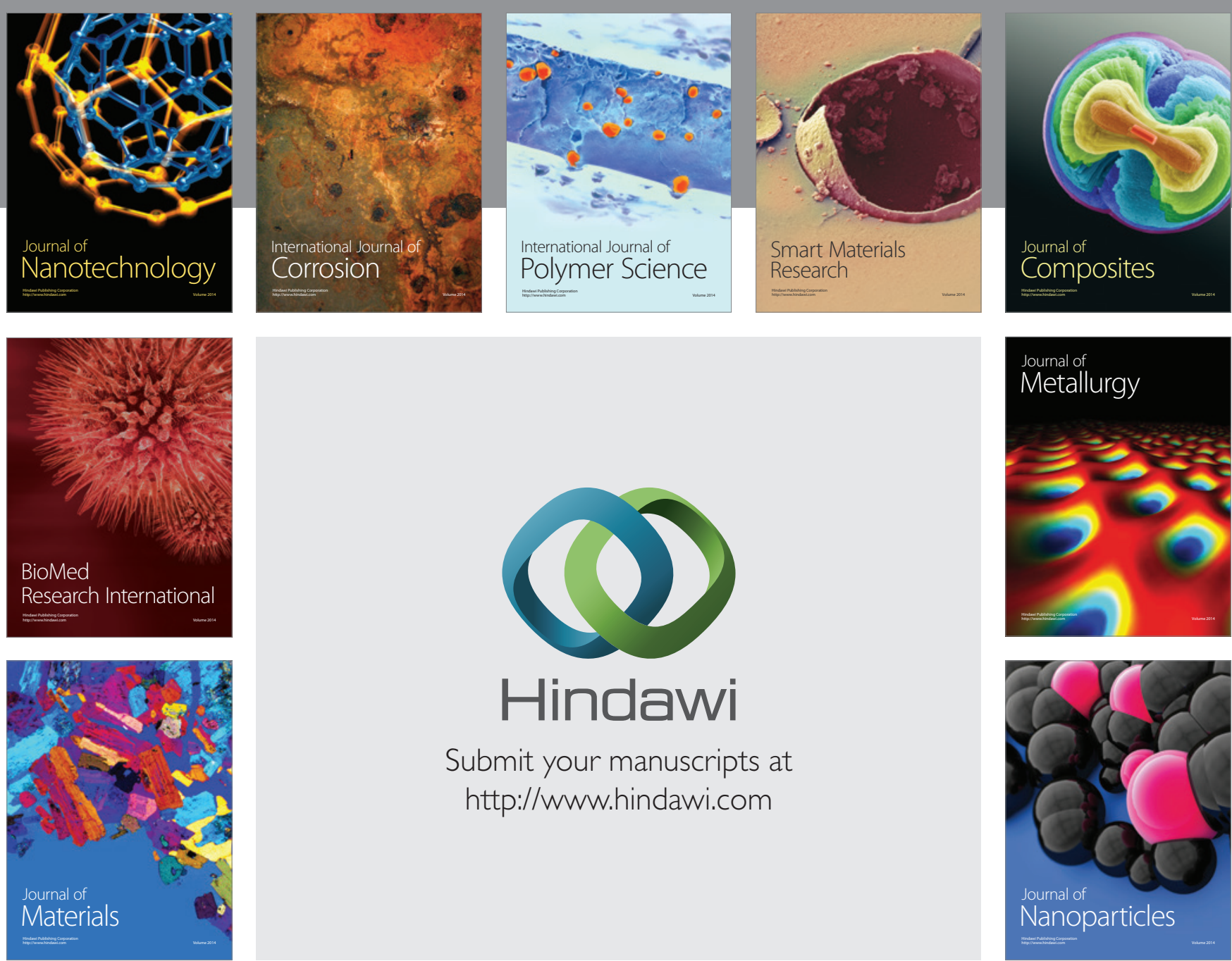

\section{Hindawi}

Submit your manuscripts at

http://www.hindawi.com

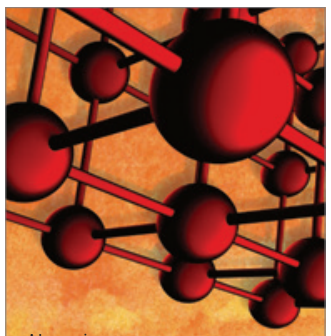

Materials Science and Engineering
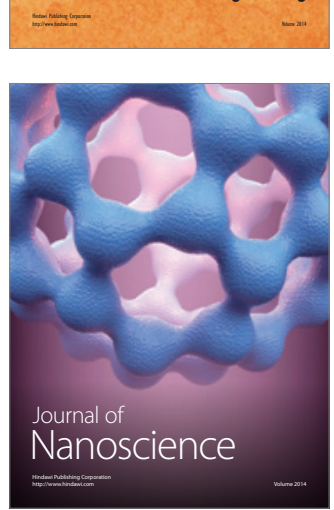
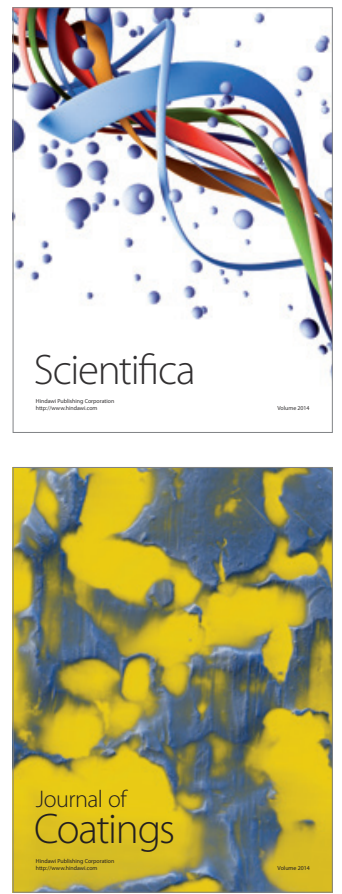
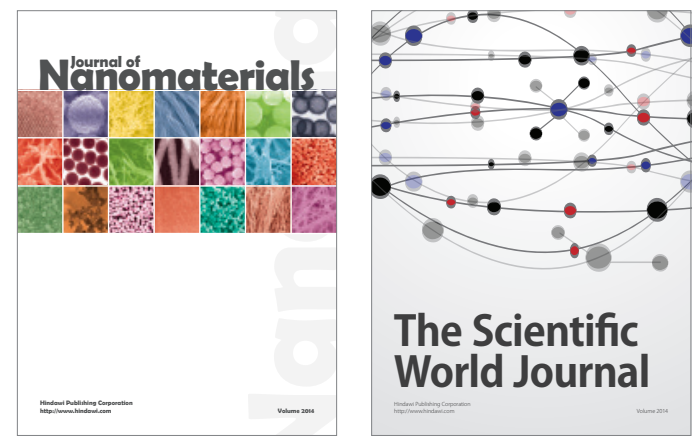

The Scientific World Journal
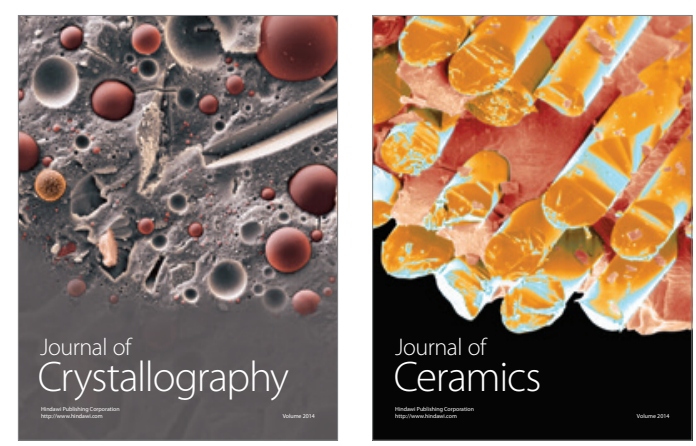
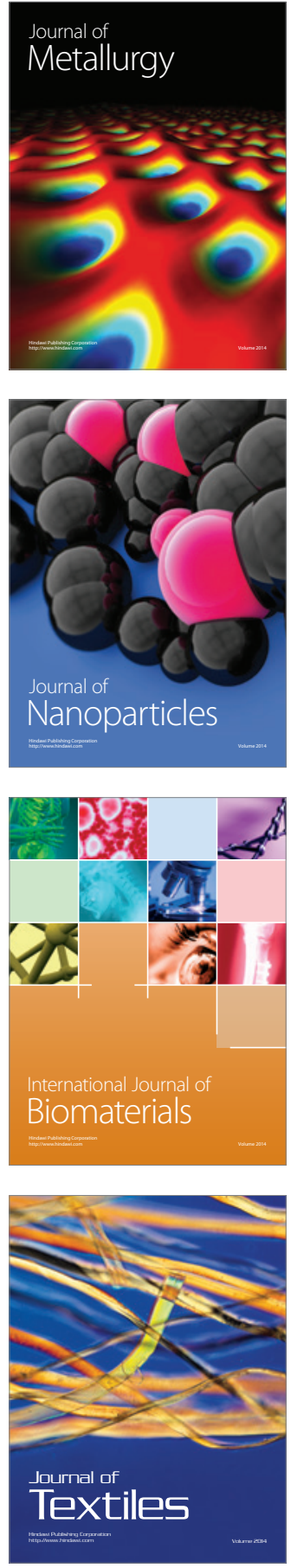